\section{Bone marrow necrosis after treatment with sulphasalazine}

We describe a patient in whom extensive necrosis of the bone marrow occurred while taking sulphasalazine. Unlike most cases of extensive bone marrow necrosis he made a full recovery.

\section{Case history}

A 22 year old Jamaican man diagnosed as suffering from ulcerative proctitis was prescribed sulphasalazine $1 \mathrm{~g}$ thrice daily and prednisolone enemas. His blood count at the time was normal. Three weeks later he presented to his family practitioner complaining of headache, sore throat, and facial swelling; amoxycillin was prescribed. His condition continued to deteriorate and a generalised rash developed. He was admitted to hospital five days later. Examination showed facial swelling, generalised tender lymphadenopathy, an exfoliative dermatitis, and a tender, enlarged liver. Haemoglobin concentration was $12.6 \mathrm{~g} / \mathrm{dl}$, white cell count $12.6 \times 10^{9} / 1$, and platelet count $224 \times 10^{9} / 1$. The differential white cell count showed only $12 \%$ neutrophils and $88 \%$ lymphocytes, some of which were atypical. Result of the Paul-Bunnell test was negative and remained so throughout. All drugs except the prednisolone enemas were stopped.

The patient took his own discharge but his symptoms worsened and he presented again, this time to St Thomas's Hospital. Results of examination, in addition to the above, included fever and severe pharyngitis. Haemoglobin concentration had fallen to $9.8 \mathrm{~g} / \mathrm{dl}$ with reticulocytopenia, platelet count to $146 \times 10^{9} / 1$, and white cell count to $3.3 \times 10^{9} / 1$. The differential white cell count showed no neutrophils, $15 \%$ monocytes, $4 \%$ atypical mononuclear cells, and the remainder lymphocytes. Haemoglobin electrophoresis showed a normal pattern. A bone marrow aspirate contained fragments that stained abnormally, lacking cellular details and surrounded by clumps of platelets. Residual haemopoietic cells were normal morphologically but an excess of atypical lymphoid cells were present. The marrow spaces of a trephine biopsy sample consisted largely of necrotic tissue, and small areas of residual haemopoietic tissue were infiltrated by lymphocytes and plasma cells (figure).

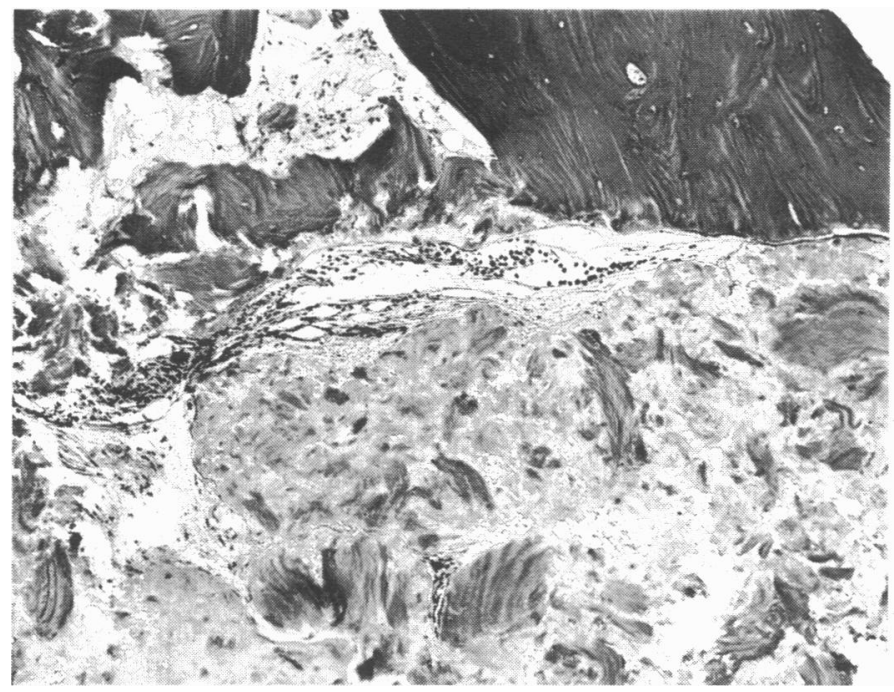

Trephine biopsy specimen showing normal bone trabeculae in upper half of field and complete marrow necrosis in lower half. Elastic van Gieson $\times 100$ (original magnification).

Staphylococcus aureus was cultured from an oropharyngeal ulcer and treatment with flucloxacillin begun. A repeat bone marrow and trephine biopsy three days later, from different sites, confirmed bone marrow necrosis at each site. Lymph node biopsy showed sinus histiocytosis. Ferrokinetic studies further to assess the extent of bone marrow necrosis could not be performed as the patient was receiving reverse barrier nursing.

Absolute neutropenia persisted for five days, recovery being preceded by a monocytosis. A blood transfusion was required to maintain his haemoglobin value, and the platelet count fell to $58 \times 10^{9} / 1$. The platelet count took the longest to return to normal, but complete recovery occurred and he subsequently remained well.

\section{Comment}

Sulphasalazine is effective against ulcerative colitis but the incidence of side effects is reportedly as high as $20 \%{ }^{1}$ In the colon sulphasalazine is broken down to sulphapyridine and 5-aminosalicylic acid. Sulphapyridine is absorbed and appears to be responsible for many of the side effects reported. These include toxic erythema, hepatitis, Heinz body haemolytic anaemia, megaloblastic anaemia, and pancytopenia. Patients who are slow acetylators tend to have high plasma sulphapyridine concentrations and to be most at risk from sulphasalazine toxicity.

The occurrence of bone marrow necrosis in an otherwise fit young man shortly after beginning a course of sulphasalazine and in the presence of other problems associated with sulphasalazine (hepatitis and exfoliative dermatitis) make it likely that sensitivity to sulphasalazine was responsible for this problem. Bone marrow necrosis is an uncommon haematological finding but was once noted after treatment with another sulphonamide, sulphathiazole. ${ }^{2}$ It is also a recognised complication of sepsis, ${ }^{2}$ but in our patient the neutrophil count was already falling before he became feverish. In other cases of sulphasalazine induced cytopenias the patients lacked precursor cells of one or more of the normal haemopoietic cell lines. ${ }^{3-5}$ Infiltration of the bone marrow by lymphocytes and plasma cells has been noted. ${ }^{5}$

Extensive bone marrow necrosis is usually associated with a high mortality and is often recognised only at necropsy. ${ }^{2}$ Recovery in our patient was fortunately complete.

We thank Drs N F Jones and N G P Slater for allowing us to report on this patient admitted under their care and for reading the manuscript. The photomicrograph was prepared with the expert help of $\mathrm{Mr} \mathrm{D}$ Turvey. Pharmacia Great Britain Ltd and the Committee on the Safety of Medicines were most helpful in providing information on previously known complications of this drug.

1 Goodman LS, Gillman A, eds. The pharmacological basis of therapeutics. 6th ed. New York: MacMillan, 1980.111

Brown CH III. Bone marrow necrosis. A study of seventy cases. Johns Hopkins Medical Fournal 1972;131:189-203.

3 Koskinen P. Pancytopenia during Salazopyrin treatment. A case report. Ann Chir Gynaecol 1954 43 (suppl 5):180-1.

4 Maddocks JL, Slater DN. Toxic epidermal necrolysis; agranulocytosis and erythroid hypoplasia associated with sulphasalazine. $\mathcal{F} R$ Soc Med $1980 ; 73: 587-8$.

5 Jamshidi K, Arlander T, Garcia MC, Windschiti HW, Swaim WR. Azulfidin agranulocytosis with bone marrow megakaryocytosis, histiocytosis and plasmacytosis. Minn Med 1972;55:545-8.

(Accepted 11 fuly 1984)

St Thomas's Hospital and Medical School, London SE1 7EH

J E W VAN DE PETTE, MRCP, MRCPATH, senior registrar, department of haematology

D T E CUNNAH, MRCP, medical registrar

T M SHALLCROSS, $M B$, BS, house officer

Correspondence to: Dr J E W Van de Pette.

\section{Diabetic thoracic polyradiculopathy presenting as abdominal swelling}

Many workers have reported abdominal pain and paraesthesiae as manifestations of diabetic neuropathies. ${ }^{1-5}$ Such truncal neuropathies are usually characterised by an absence of clinical features of motor abnormality, ${ }^{24}$ the coexistence of peripheral and autonomic neuropathies, ${ }^{1-5}$ and a good prognosis for recovery. ${ }^{1-5}$ We describe a patient with type 2 diabetes and truncal polyradiculopathy who presented with an abdominal swelling but no other symptoms of peripheral or autonomic neuropathy.

\section{Case report}

A 71 year old white man with a 15 year history of type 2 (non insulin dependent) diabetes mellitus was referred for investigation of a right sided abdominal swelling. Six weeks previously he had noticed a bulge in the right side of his abdomen, which became more prominent when he coughed or tried to sit up from the supine position. There was no localised pain, though a 